$4^{\text {th }}$ International Meeting on Calcitonin Gene-Related Peptide (CGRP)

TheScientificWorld (2001) 1(S1), 9

ISSN 1532-2246; DOI 10.1100/tsw.2001.442

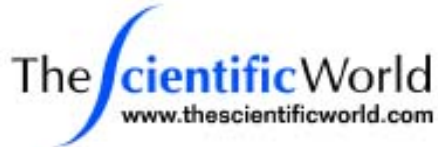

\title{
CALCITONIN/AMYLIN RECEPTORS AND RAMPS
}

\author{
Patrick M. Sexton \\ Howard Florey Institute of Experimental Physiology and Medicine, The University of Melbourne, \\ Victoria 3010, Australia
}

Our understanding of $\mathrm{G}$ protein-coupled receptor function has recently expanded to encompass novel protein interactions that underlie both cell surface receptor expression and the exhibited phenotype. The most notable examples are those involving receptor activity modifying proteins (RAMPs). RAMP association with the calcitonin receptor-like receptor (CRLR) traffics this receptor to the cell surface, where individual RAMPs dictate the expression of unique phenotypes.

It is now evident that RAMPs can interact with receptors other than CRLR. Expression of amylin receptor phenotypes requires the coexpression of RAMPs with the calcitonin receptor (CTR) gene product. However, as seen for CRLR, the phenotype engendered by individual RAMPs were distinct. In COS-7 cells, RAMP1 and RAMP3 induced amylin receptors from

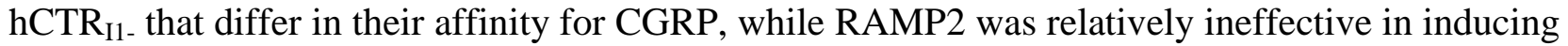
amylin receptor phenotype. More recent work has revealed that RAMP2 can also induce an amylin receptor phenotype, which is distinct from either the RAMP1 or RAMP3 induced receptors, however, the efficacy of RAMP2 was highly dependent upon the cellular backgound and the isoform of CTR used in the study, with the hCTR $_{11+}$ isoform yielding amylin receptors with each of the RAMPs in all cellular backgrounds.

The most common human CTR isoforms differ by the presence $\left(\mathrm{hCTR}_{\mathrm{I} 1+}\right)$ or absence $\left(\mathrm{hCTR}_{\mathrm{I1}-}\right)$ of a 16 amino acid insert in intracellular domain 1 . The major consequence of this interaction is alteration to the efficiency of receptor-G protein coupling. Consequently, we speculated that $G$ protein level and/or type could influence the observed receptor phenotypes. Cotransfection of Ga protein-hCTR $\mathrm{I1}_{\text {- }}$ bicistronic vectors with RAMP2, or triple transfection of $\mathrm{G}$ protein/receptor/RAMP2 into COS-7 cells, caused a significant increase in specific amylin binding vs. RAMP2/CTR alone, indicating that $\mathrm{G}$ protein was an important component of the expressed receptor phenotype. The level of induced amylin receptor binding, however, varied depending upon the $G$ protein coexpressed. For example, the level of RAMP3-induced amylin binding, in the presence of Gq, was less than that induced by RAMPs 1 and 2, whereas, with Gi overexpression relatively similar levels of induced receptor were seen.

Analysis into functionally important domains within the RAMPs, using chimeras where the N-terminal domain has been switched between RAMPs 1 and 2, indicate that the N-terminus is the principal region responsible for altering receptor phenotype. Only constructs containing the $\mathrm{N}$ terminus of RAMP1 induced specific ${ }^{125}$ I-CGRP binding when cotransfected with CRLR, while constructs with the RAMP2 amino terminus behaved predominantly like wild-type RAMP2. Similarly, the RAMP amino terminus essentially dictated the type of amylin receptor induced following cotransfection with $\mathrm{hCTR}_{\mathrm{I1} \text {-. }}$ More striking is the effect on induction of amylin receptors, where, despite displaying phenotypes according to the $\mathrm{N}$-terminal domain present, the level of amylin binding was dictated by the transmembrane/C-terminal domain present. Thus, both regions of RAMP are functionally important, with the transmembrane/C-terminal domain likely to 
be the primary site for RAMP-receptor interaction (at least for the CTR) and/or potentially orientation of the RAMP-receptor interaction, with subsequent interaction of the $\mathrm{N}$-terminal domain as the major determinant of phenotype. 

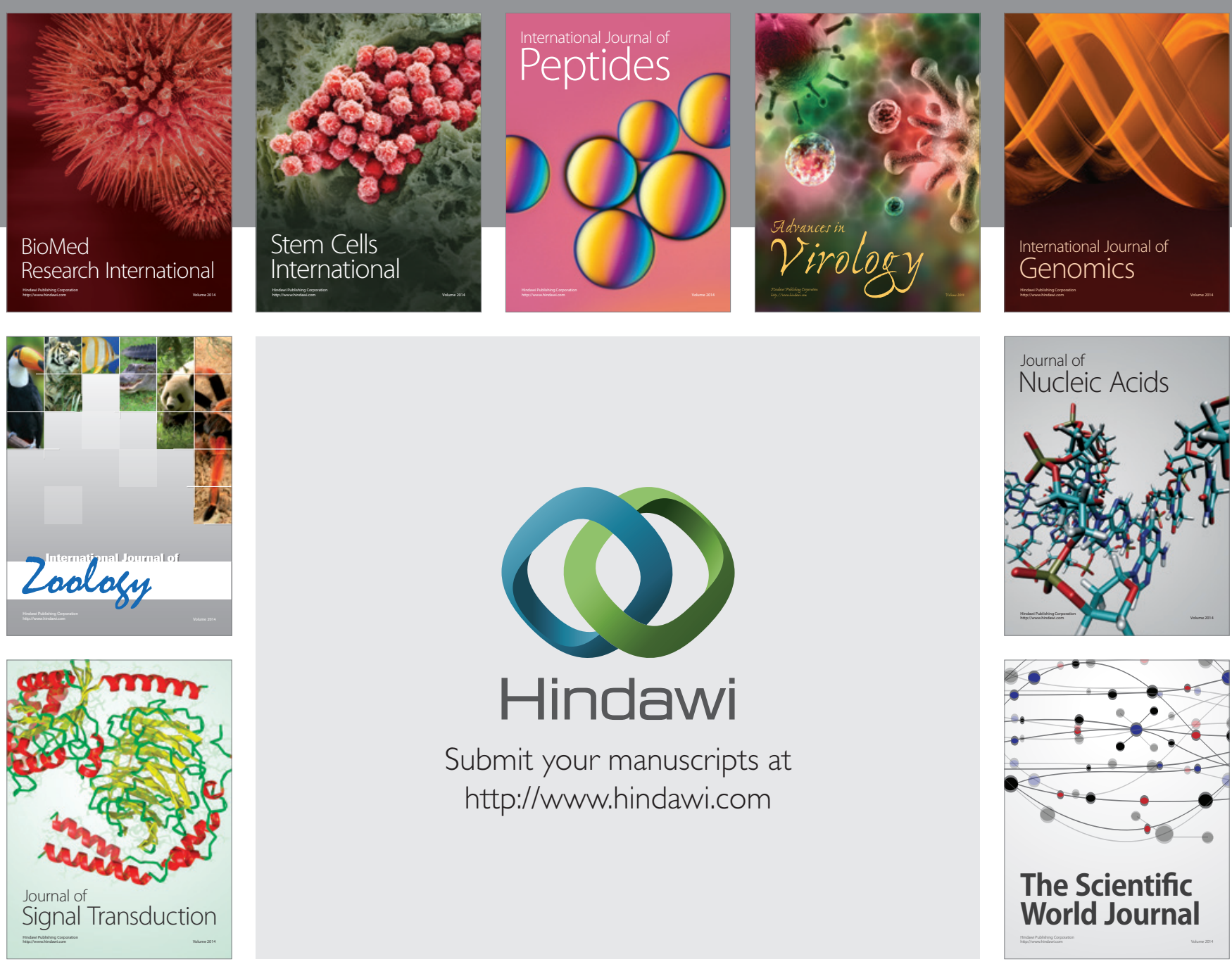

Submit your manuscripts at

http://www.hindawi.com
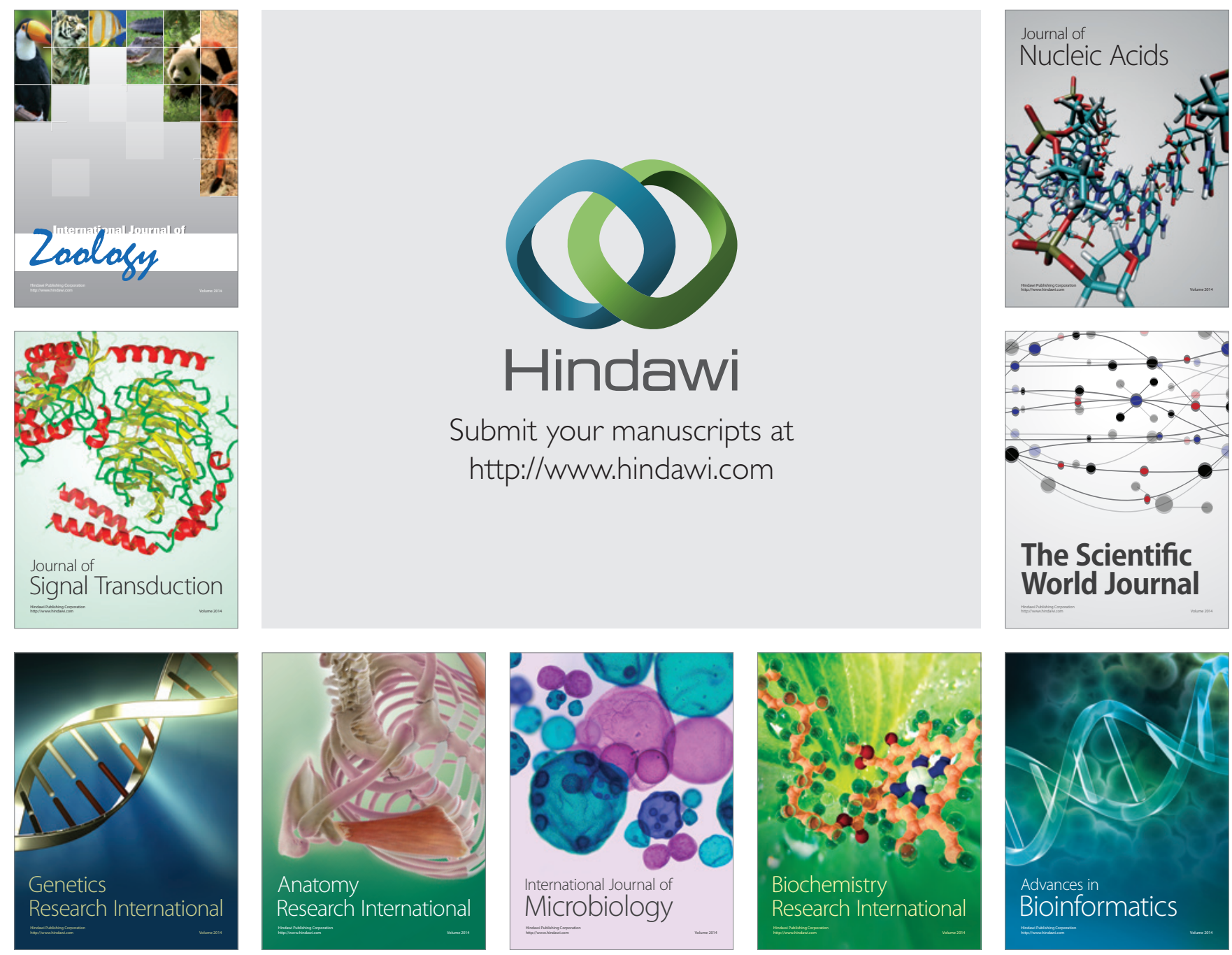

The Scientific World Journal
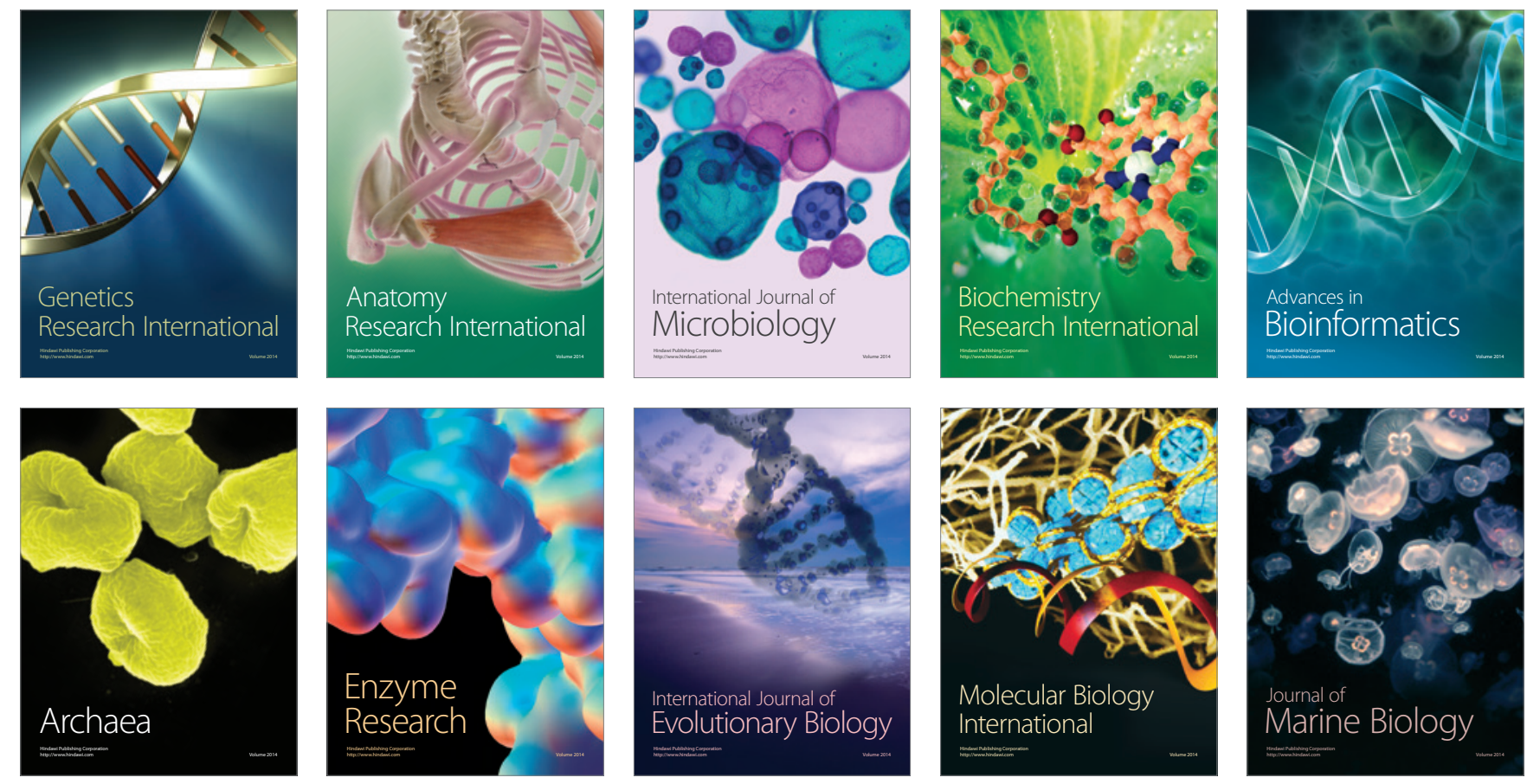